\title{
Effectiveness of Teaching Style: An Alternative Breaststroke Swimming Learning Model in Higher Education
}

\author{
Pringgo Mardesia ${ }^{1,2, *}$, Firmansyah Dlis ${ }^{1}$, Abdul Sukur $^{1}$, Rusdi $^{3}$, Abdillah $^{3}$ \\ ${ }^{1}$ Department of Physical Education, Universitas Negeri Jakarta, Indonesia \\ ${ }^{2}$ Faculty of Sports Science, Universitas Negeri Padang, Padang, 25132, West Sumatra, Indonesia \\ ${ }^{3}$ Physical Education Program, Faculty of Health Sports Education, IKIP PGRI Pontianak, Pontianak, 78116, \\ West Kalimantan, Indonesia
}

Received August 7, 2021; Revised September 11, 2021; Accepted October 17, 2021

\section{Cite This Paper in the following Citation Styles}

(a): [1] Pringgo Mardesia, Firmansyah Dlis, Abdul Sukur, Rusdi, Abdillah, "Effectiveness of Teaching Style: An Alternative Breaststroke Swimming Learning Model in Higher Education," International Journal of Human Movement and Sports Sciences, Vol. 9, No. 6, pp. 1236 - 1243, 2021. DOI: 10.13189/saj.2021.090618.

(b): Pringgo Mardesia, Firmansyah Dlis, Abdul Sukur, Rusdi, Abdillah (2021). Effectiveness of Teaching Style: An Alternative Breaststroke Swimming Learning Model in Higher Education. International Journal of Human Movement and Sports Sciences, 9(6), 1236 - 1243. DOI: 10.13189/saj.2021.090618.

Copyright $\mathrm{C} 2021$ by authors, all rights reserved. Authors agree that this article remains permanently open access under the terms of the Creative Commons Attribution License 4.0 International License

\begin{abstract}
This study aims to see the effectiveness of inclusive and command teaching styles in improving breaststroke swimming learning outcomes for students of Sports Education, Universitas Negeri Padang. This study used an actual experiment research design; posttest only control group designing, which received the inclusive style teaching method and the control group, and the command style teaching method. Participants in this study were students of Sports Education who were studying at Universitas Negeri Padang. The total number of participants is 32. Sixteen participants were in the experimental group (aged 19-20 years), while the control group consisted of 16 participants (mean age 19-20 years). The research was conducted for 16 weeks ( 2 hours per week) by completing pre-test and post-test. The data analysis was started by testing the normality of the variables and then testing the equivalence of the covariance matrix. The results showed that the inclusive teaching style gave positive results compared to the inclusive teaching style on breaststroke swimming learning outcomes. Because by using an inclusive teaching style, students can choose the desired level of learning based on their abilities. The results of this study provide an implication, especially as an alternative to increase the effectiveness of learning in breaststroke swimming for college students.
\end{abstract}

Keywords Teaching Style, Inclusive, Commando, Breaststroke Swimming and Higher Education

\section{Introduction}

Swimming has many benefits in physiological, psychological, social and cognitive aspects [1]. In addition, swimming exercises also make a positive contribution to the improvement of some basic aquatic skills (breath control combined with face dipping and eye-opening; horizontal buoyancy; body position when sliding on the stomach; body position when sliding on the back; foot kick with breath control on the back, ventral body position) [2]. Breaststroke swimming is done cyclically and continuously, starting from the initial stance, strokes and footwork regularly [3]. In another study, it was explained that the synergism of muscle coordination during breaststroke swimming was not too influenced by skill. Still, other factors from the upper and lower limbs became an essential indication in implementing breaststroke swimming [4]. In teaching swimming, the relationship between anthropometric characteristics and performance is a valuable marker for identifying talent for involving 
children in the long-term athlete development process [5]. Therefore, the form of teaching carried out must also be able to adapt to the actual situation.

There is a sizeable intra-cyclic velocity variation [6] of the body's center of mass [7]. Breaststroke swimming is a rhythmic movement in phases involving a stable and flexible mode of coordination between the upper and lower extremities. These movements arise due to action between the mechanical properties of water and the intrinsic dynamics of the body [8], [9]. One of the main determinants of performance is the swimmer's ability to efficiently coordinate the upper and lower limbs, especially during the non-push/recovery phase [10]. Therefore, complete information about teaching styles during teaching breaststroke swimming can be helpful for athletes and coaches.

Teaching styles have a huge role in improving students' learning abilities; with these various learning styles, it is hoped that students can find the most appropriate teaching style to enhance their abilities [11]. The spectrum of teaching styles for physical educators serves as a 'toolbox' to meet students' various needs and goals in physical education [12]. Mosston's influential Teaching Style spectrum is a guide for teaching decisions in Physical Education [13]. According to Moston, several teaching styles can be applied by lecturers in learning, such as the command style, the practice style, the reciprocal style, the self-check style, the inclusion style, the guided discovery style, the divergent style, the individual program style (the going beyond style) [14]. In addition to teaching style, one of the critical factors in the teaching and learning process seems to be variations in water depth [2]. Therefore, it is also essential for an instructor to be able to know it. In addition, a teacher must consider the importance of teaching style and its impact on advancing education [15]. The right and appropriate teaching style and achieving learning targets can also motivate students to do more in learning [16]. Selected theoretical assumptions related to the Teaching Style Spectrum are very important for pursuing knowledge of effective instructional strategies [17].

The command and inclusion teaching style can teach breaststroke swimming to students taking introductory swimming courses if you pay attention. The command style is the application of a teaching style in which the educator fully controls learning. The lecturer prepares all aspects of teaching, and he is fully responsible and takes the initiative for education and monitors the significant progress of the development of his students. While the inclusive teaching style is a teaching guide used by lecturers to present learning materials in detail, explaining the level of difficulty [14], [18]. Students are given the freedom to choose and determine the level of difficulty at which students start learning and are also given the freedom to decide how many times students must repeat the movement in learning a movement technique in each meeting.
The dominant command style will be effective and time-efficient, but movement skills are learned by experimentation and refinement, imitation and exploration, experimentation and adaptation, observation and adjustment to feedback [19]. Therefore, a dominating methodology with a commando style may conflict with balancing programs whose goals stem from the science and art of human movement [19].

In the inclusive teaching style, students are given alternative difficulty levels to choose from when doing assignments [14], [17]. After observing the demonstration, students enter the task at the level of difficulty they deem to be successful. After practicing for several trials, they decide whether to continue performing the study at the same, lower, or higher level of difficulty [17]. The purpose of the inclusion style is to include students at the appropriate skill level [17]. In the inclusion style, students are given alternative difficulty levels to choose from when doing the task [12], [14]. Furthermore, in the Inclusion style, responsibility for decisions that affect the teaching environment is shared by teachers and students [20].

Based on previous studies that used less complex teaching styles, such as the commando teaching style, we hypothesized that the inclusive teaching style would provide differences in breaststroke swimming learning outcomes for students taking elementary level swimming.

Teaching style is the main axis in the implementation of education (especially in higher education). Because teaching can determine the end of a learning outcome [21]. Until now, there have not been many studies that have really focused on swimming teaching styles and their effects. This study has implications for the appropriate teaching style and can improve the ability to learn breaststroke swimming in college students.

\section{Materials and Methods}

\subsection{Research Design}

This study used an actual experiment research design; posttest only control group designing, which received the inclusive style teaching method and the control group, which received the command style teaching method. In consideration of ethical research, research content, design of research activities, protection of privacy and information for participants, and freedom for participants to withdraw at any time may be used. The study continued with the approval of all samples to be used in this study. The pre-test was carried out in the experimental and control groups before starting the study, and the post-test was also carried out after 16 weeks of treatment.

\subsection{Population and Sampling}

Participants in this study were students of Sports 
Education who were studying at Universitas Negeri Padang. To reduce the interference of irrelevant variables, students have not received the command and inclusion style teaching method before. The total number of participants is 32 participants. Sixteen participants were in the experimental group (aged 19-20 years), while the control group consisted of 16 samples (mean age 19-20 years). The experimental and control groups underwent 16 weeks of learning ( 2 hours per week).

\subsection{Procedure}

The implementation of data collection was carried out by agreeing to the Universitas Negeri Padang to use students as research samples. Next, the researcher asked the participants for consent to follow the research procedure from start to finish. Participants were taken from swimming lessons with 32 participants ( 21 boys and 11 girls) then divided into two groups using a random sampling technique. After obtaining two groups of participants with the same number (16), each was given directions related to the program to be run from each group. The implementation of the research from each group was 16 weeks (2 hours per week).

In the treatment group using inclusion, participants were introduced to various tasks and then encouraged to determine their level of performance. Inclusive learning style is a learning style used by teachers, by presenting learning materials in detail and offering different levels of difficulty sequentially, which aims to make students creative and get convenience in learning a movement skill as well as participants are given the freedom to choose and determine at the level of difficulty in starting to learn a movement, as well as being given the freedom and flexibility to determine how many times the participant must repeat the action, in learning a movement technique. In the inclusion style, students are given alternative levels of difficulty to choose when doing the task [12], [14].

The control group uses a command style, namely learning, that the instructor fully carries out and controls. Participants only do the exercises by following the instructions that have been given. The goal is a careful appearance, and the teacher prepares all aspects of teaching fully responsible for teaching and monitoring the significant progress of the development of the participants. In the commando-style of teaching, participants learn to perform tasks accurately and quickly as presented by the instructor [12].

After each group was given a program for 16 weeks, participants were faced with a final assessment (posttest). These results will later determine whether the participants have increased abilities or even what kind of teaching style is better to use.

\subsection{Instrument}

The instrument used is the adopted swimming assessment instrument [21]. All athletes were evaluated individually by two raters (swimming coaches). The raters are not involved in any way in this test. Each participant is identified by a number only (without using a name). Each observer recorded the time and assessed the results of the breaststroke swimming learning on the standard score sheet [21]. Before data collection, raters were trained using video analysis as an example to ensure rater reliability and one scoring sheet per trial.

From the existing instruments, to ensure that it is again suitable for use, the researchers carried out a re-testing stage by obtaining Cronbach's Alpha value of 0.954 with a total of 30 items.

\subsection{Data Analysis}

Statistical analysis of the data was made using the SPSS version 24 program. Significance was determined at the 0.05 level. Before the data was analyzed, the data was tested for variance. The Kolmogorov-Smirnov test (KS-test) on the normality test of the variables and the covariance matrix equivalence test was performed. The non-significant value $(p<0.05)$ indicates that the data is not significantly different from the normality of multivariate variables so that parametric tests can be applied.

\section{Result}

The primary influence in this study is the difference in the learning outcomes of breaststroke swimming given the inclusive and command teaching style. Based on the 16-week program, the results of the differences between the two teaching styles can be seen in Table 1 below:

Table 1. Tests of Normality

\begin{tabular}{cccccccc}
\hline \multirow{2}{*}{ Teaching Style } & \multicolumn{3}{c}{ Kolmogorov-Smirnov $^{\mathrm{a}}$} & \multicolumn{3}{c}{ Shapiro-Wilk } \\
\cline { 2 - 7 } & \multicolumn{2}{c}{ Statistic } & df & Sig. & Statistic & df & Sig. \\
\cline { 2 - 7 } Command &, 133 & 16 &, $200^{*}$ &, 937 & 16 &, 311 \\
Inclusion &, 118 & 16 &, $200^{*}$ &, 968 & 16 &, 811 \\
\hline
\end{tabular}

*. This is a lower bound of the true significance.

a. Lilliefors Significance Correction

From table 2 Tests of Normality, it is obtained: the statistical price given by the command and inclusion teaching style for Kolmogorov-Smirnov is 0.133 and 0.118 and sig or $p$-value $=0.200$, and $0.200>0.05$ for the results of breaststroke swimming learning outcomes for sports education students Universitas Negeri Padang H0 is accepted or not significant. Thus, the data on breaststroke swimming learning outcomes for Universitas Negeri Padang, sports education students were normally distributed. For more details, see Figure 1 of the normal Quantile and Quantile (Q-Q) plot below: 

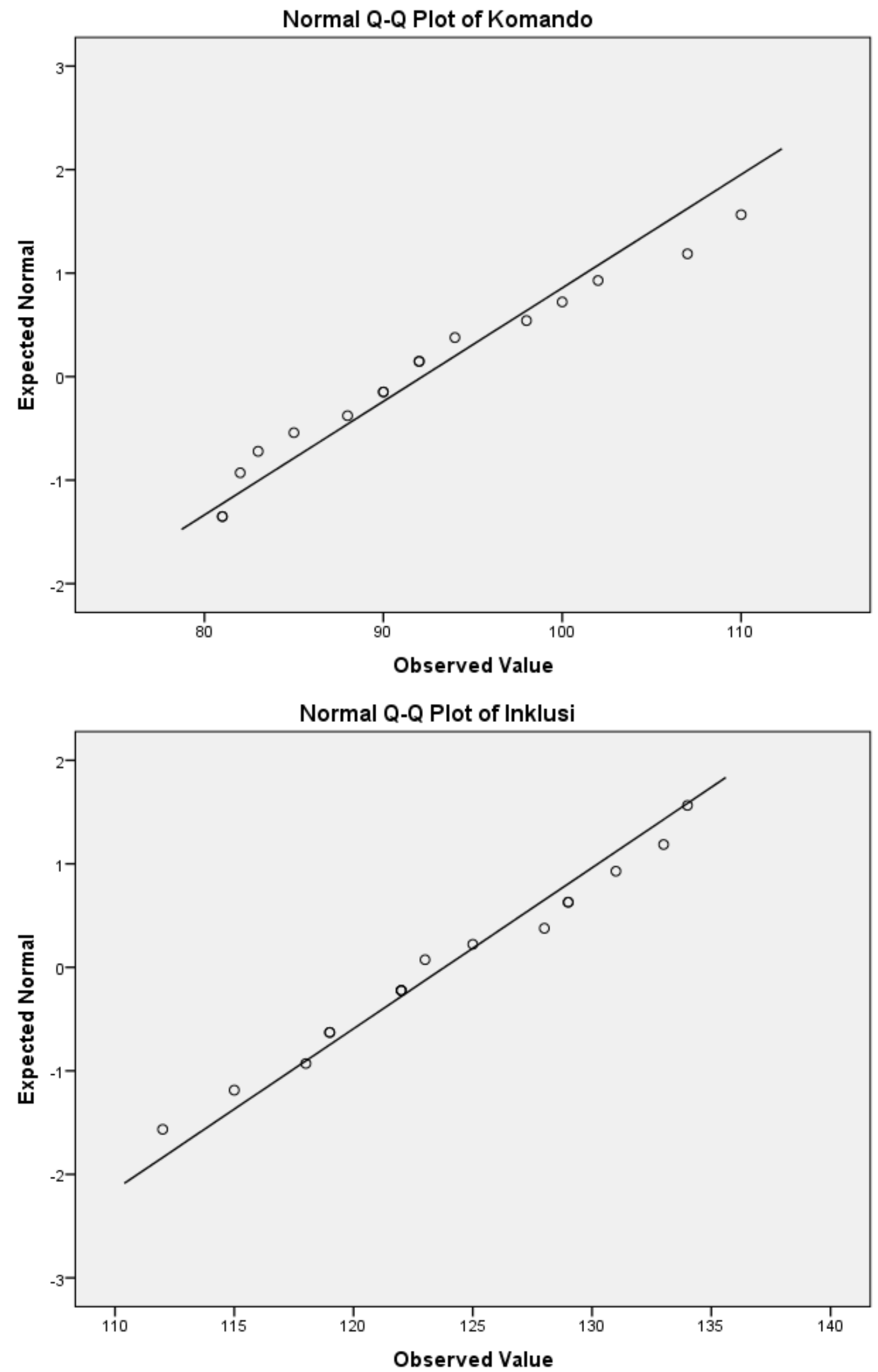

Figure 1. Quantile and Quantile Normal Diagram (Q-Q) Command and Inclusion 
In addition to the normal Q-Q Plot, testing the normality of the student breaststroke swimming learning outcomes data can also be seen from the Detrended Normal Q-Q Plot. The indicator is that the data is declared normally distributed if the data distribution in the form of dots does not form a specific pattern and gathers around a horizontal line through the zero points.

Table 2. Test of Homogeneity of Variance

\begin{tabular}{cccc}
\hline Levene Statistic & df1 & df2 & Sig. \\
\hline 1,555 & 1 & 30 &, 222 \\
\hline
\end{tabular}

Table 2 above is the result of the data homogeneity test that has been carried out. Based on table 2, the results of the lavender statistical test are all criteria with sig values. All above 0.05. Because of the value of sig. more significant than 0.05 , it can be concluded that the research data using the command and inclusion teaching style came from a homogeneous population.

\begin{tabular}{cccccc}
\multicolumn{7}{c}{ Table 3. Group Statistics } \\
\hline & Treatment & $\mathbf{N}$ & Mean & $\begin{array}{c}\text { Std. } \\
\text { Deviation }\end{array}$ \\
\hline $\begin{array}{c}\text { Learning Outcomes } \\
\text { of Breaststroke } \\
\text { Swimming }\end{array}$ & Command & 16 & 92,19 & 9,123 & 2,281 \\
\hline
\end{tabular}

In table 3, group statistics explain the learning outcomes of breaststroke swimming with a commando teaching style of 92.19 and a standard deviation of 9.123 . Then the teaching style with the inclusion method is 123.81, and the standard deviation is 6.431 . This means that descriptively, the learning outcomes of breaststroke swimming taught with the inclusive teaching style are higher and more consistent than the commando teaching style.

In table 4 , the independent samples test column Levene's Test for Equality of Variances obtains a value of $\mathrm{F}=1.555$ with sig. or $\mathrm{p}$-value $=0.222>0.05$, which means that the populations of the two groups are the same or homogeneous. Because the data variance is homogeneous, the Equal variances assumed column will be selected and, in the t-test for Equality of Means line and obtained a value of $\mathrm{t}=11,333, \mathrm{db}=30$ and sig (2tailed) or $\mathrm{p}$-value $=$ $0.000 / 2=0.000<0.05$, or H0 is rejected. Thus, the proposed hypothesis is tested by the data. So, it can be concluded that the learning outcomes of breaststroke swimming which are taught using the inclusive teaching style, are higher than the teaching style with the command method.

Table 4. Independent Samples Test

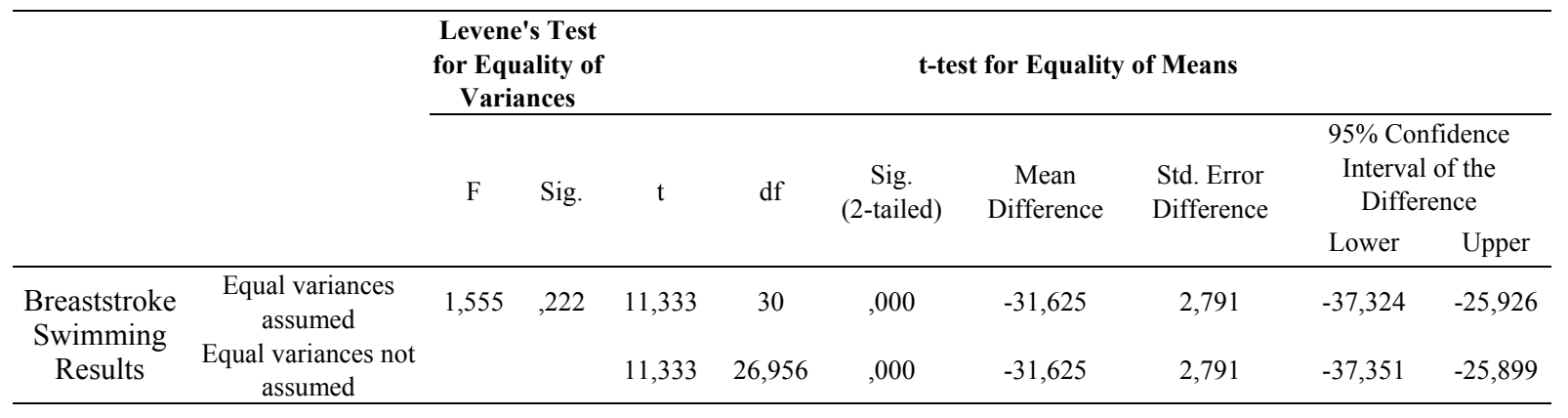




\section{Discussion}

A teacher or instructor needs more consideration and attention to know and see the importance of teaching style and how and how to implement it [23], [24]. Another study also explains that the influence of the teacher's teaching style has a significant impact on improving learning outcomes [23]. A teacher or instructor must manage and apply different constraint manipulations at other times in the context of practice, i.e., when planning before/after a learning session (designing a practice structure) and in interactions during the session [24].

Over the past decade, researchers have explored the extent to which the Spectrum teaching style is perceived and used by physical education teachers from various countries around the world. [25]. Likewise, with the results of research that has been carried out for 16 weeks, getting a difference in learning outcomes with the application of the command and inclusion teaching style.

Learning outcomes with the inclusion method used in breaststroke swimming lessons can give categorized results as good. This can be seen from the difference in the average results of the pre and post-test. An inclusive teaching style was reported in a study that explained that students felt more physically and cognitively engaged in an inclusion style lesson than in a command and practice style lesson. [12]. The inclusive teaching style is considered more interesting and challenging because students prefer to make decisions about their tasks [26].

An inclusive teaching style seems to strongly influence the development of swimming skills at low to high activity levels. To maximize physical activity, pools should be designed with a variety of swimming equipment [27]. Access to appropriate facilities for physical activity in the water and physically active play has been identified as a critical determinant of participation for physical development [28].

Regarding the inclusive teaching style, it can be explained that the inclusive teaching style with others requires solving several social problems, such as deciding what to teach, who can swim, when to start, when to stop, and the rules of learning [29]. Solving these dilemmas and conflicts that arise in inclusive learning can encourage students to work together. This process can foster various social and emotional abilities such as empathy, flexibility, self-awareness, and self-regulation [30]. The inclusive teaching style is presented in detail from low to more complex levels [30], [31].

Inclusive teaching style seems to strongly influence the development of students' abilities in swimming, where students learn at low to high activity levels. To maximize physical activity for students, pools should be designed with a variety of swimming equipment [27]. Access to appropriate facilities for physical activity in the water and physically active play has been identified as a critical determinant of participation for physical development [28].
Physical activity in the aquatic environment is significant for human health [32]. Therefore, the determination of the teaching style will also have a significant influence on the learning outcomes achieved. The best form and way to determine the effectiveness of motor learning outcomes is with previous student experiences, which can provide perceptual and motor elements to be transferred to new motor skills [33]. In addition, to achieve a breaststroke swimming learning result, it is necessary to relate psychological factors (such as discipline [34] and the power of motivation) in learning. Approaches using psychological factors are proven to increase and better interest in sports [35]. So in water sports, it is also essential to have the perception of competence and motivation to master swimming abilities and skills (one of which is breaststroke swimming) [36] [39].

\section{Conclusions}

The current findings suggest that both teaching styles promote motor acquisition, but the inclusive teaching style appears to produce superior value over command. Inclusive teaching style significantly improves breaststroke swimming learning outcomes for sports education students, Universitas Negeri Padang. This can be seen from the difference between the pre and post-test of male and female students. By using the teaching style of learning outcomes and skills possessed by sports education students, Universitas Negeri Padang is better than trained students using the command style.

On the other hand, the actual command style cannot be wholly said to be "bad/failed" because the command style only follows the instructions or programs that have been given. So, it is necessary to evaluate the schedule provided in terms of content, suitability of the program to its implementation. Because the authentic commando teaching style can develop various skills, both physical, motor, knowledge, and social if done correctly and adequately. For this reason, a structured breaststroke swimming learning program or design is needed, which contains elements of physical education learning such as; affective, cognitive, and psychomotor.

Recommendations given by the author for further research related to teaching styles in swimming are significant to be provided. As a trainer, instructor or teacher, determining the right teaching style has a significant influence on the success of a lesson. Therefore, it is essential to pursue knowledge of effective instructional strategies [17] to achieve the desired learning objectives. Things that need to be looked at are other teaching styles that can be compared with the research that has been done. 


\section{Acknowledgements}

Thank you to all students and lecturers involved in this research and researchers who support each other and provide information about the research findings.

\section{REFERENCES}

[1] M. P. De Morais and G. M. Rodrigues, "Strategies to teach swimming to people with Spinal Cord Injury (SCI)," Motriz. Rev. Educ. Fis., vol. 24, no. 4, pp. 1-5, 2018, doi: $10.1590 /$ S1980-6574201800040006.

[2] H. A. Rocha, D. A. Marinho, N. D. Garrido, L. S. Morgado, and A. M. Costa, "The acquisition of aquatic skills in preschool children: Deep versus shallow water swimming lessons," Motricidade, vol. 14, no. 1, pp. 66-72, 2018, doi: 10.6063/motricidade. 13724.

[3] M. Strzała et al., "Swimming speed of the breaststroke kick," J. Hum. Kinet., vol. 35, no. 1, pp. 133-139, 2012, doi: 10.2478/v10078-012-0087-4.

[4] J. R. Vaz, B. H. Olstad, J. Cabri, P. L. Kjendlie, P. Pezarat-Correia, and F. Hug, "Muscle coordination during breaststroke swimming: Comparison between elite swimmers and beginners," J. Sports Sci., vol. 34, no. 20, pp. 1941-1948, 2016, doi: 10.1080/02640414.2016.1143109.

[5] S. Sammoud, A. M. Nevill, Y. Negra, R. Bouguezzi, H. Chaabene, and Y. Hachana, "100-m breaststroke swimming performance in youth swimmers: The predictive value of anthropometrics," Pediatr. Exerc. Sci., vol. 30, no. 3, pp. 393-401, 2018, doi: 10.1123/pes.2017-0220.

[6] C. Schnitzler, L. Seifert, V. Ernwein, and D. Chollet, "Arm coordination adaptations assessment in swimming," Int. J. Sports Med., vol. 29, no. 6, pp. 480-486, 2008, doi: 10.1055/s-2007-989235.

[7] H. Leblanc, L. Seifert, C. Tourny-Chollet, and D. Chollet, "Intra-cyclic distance per stroke phase, velocity fluctuations and acceleration time ratio of a breaststroker's hip: A comparison between elite and nonelite swimmers at different race paces," Int. J. Sports Med., vol. 28, no. 2, pp. 140-147, 2007, doi: 10.1055/s-2006-924205.

[8] L. Seifert, D. Chollet, and B. G. Bardy, "Effect of swimming velocity on arm coordination in the front crawl: A dynamic analysis," J. Sports Sci., vol. 22, no. 7, pp. 651660, 2004, doi: 10.1080/02640410310001655787.

[9] S. W. Oxford, R. S. James, M. J. Price, C. J. Payton, and M. J. Duncan, "Changes in kinematics and arm-leg coordination during a 100-m breaststroke swim," J. Sports Sci., vol. 35, no. 16, pp. 1658-1665, 2016, doi: 10.1080/02640414.2016.1229012.

[10] J. Komar, R. H. Sanders, D. Chollet, and L. Seifert, "Do qualitative changes in interlimb coordination lead to effectiveness of aquatic locomotion rather than efficiency?," J. Appl. Biomech., vol. 30, no. 2, pp. 189-196, 2014, doi: 10.1123/jab.2013-0073.

[11] R. Rusdi, F. Dlis, J. Lubis, A. D. Nata, and W. Whalsen,
"The Effect of Teaching Style Pratice, Reciprocity, Inclusion and Learning Motivation on Butterfly Swimming Skills," Kinestetik J. Ilm. Pendidik. Jasm., vol. 4, no. 2, pp. 63-69, 2020, doi: 10.33369/jk.v4i2.12574.

[12] B. Sanchez, M. Byra, and T. L. Wallhead, "Students' perceptions of the command, practice, and inclusion styles of teaching," Phys. Educ. Sport Pedagog., vol. 17, no. 3, pp. 317-330, 2012, doi: 10.1080/17408989.2012.690864.

[13] F. B. El Khouri, C. de M. M. Junior, G. M. Rodrigues, and M. L. de J. Miranda, "Effects of command and guided discovery teaching styles on acquisition and retention of the handstand," IOSR J. Humanit. Soc. Sci., vol. 1, no. 6, pp. 27-32, 2012, doi: 10.9790/0837-0162732.

[14] M. Mosston and S. Ashworth, Teaching Physical Education, Fourth Edi. 866 Third avenue, 1994.

[15] A. Arbabisarjou, M. Akbarilakeh, F. Soroush, and A. Payandeh, "Validation and normalization of grashariechmann teaching style inventory in faculty members of zahedan university of medical sciences," Adv. Med. Educ. Pract., vol. 11, pp. 305-312, 2020, doi: 10.2147/AMEP.S244313.

[16] M. Angelica and I. Katz, "Emotion regulation and need satisfaction shape a motivating teaching style," Teach. Teach. Theory Pract., vol. 00, no. 00, pp. 1-18, 2020, doi: $10.1080 / 13540602.2020 .1777960$.

[17] M. Byra, B. Sanchez, and T. Wallhead, "Behaviors of students and teachers in the command, practice, and inclusion styles of teaching: Instruction, feedback, and activity level," Eur. Phys. Educ. Rev., vol. 20, no. 1, pp. 319, 2014, doi: 10.1177/1356336X13495999.

[18] O. Gilor and M. Katz, "From normalisation to inclusion: effects on pre-service teachers' willingness to teach in inclusive classes," Int. J. Incl. Educ., vol. 25, no. 4, pp. 466481, 2021, doi: 10.1080/13603116.2018.1559365.

[19] R. J. Ritson, "Psychomotor Skill Teaching: Beyond the Command Style," J. Phys. Educ. Recreat. Danc., vol. 58, no. 6, pp. 36-37, 1987, doi: 10.1080/07303084.1987.1060956 9.

[20] M. Byra and J. Jenkins, "Matching Instructional Tasks to Learner Ability: The Inclusion Style of Teaching," J. Phys. Educ. Recreat. Danc., vol. 71, no. 3, pp. 26-30, 2000, doi: 10.1080/07303084.2000.10605108.

[21] M. Leyton-Román, J. J. L. González-Vélez, M. Batista, and R. Jiménez-Castuera, "Predictive model for amotivation and discipline in physical education students based on teaching-learning styles," Sustain., vol. 13, no. 1, pp. 1-14, 2021, doi: 10.3390/su13010187.

[22] H. Takagi, S. Sugimoto, N. Nishijima, and B. Wilson, "Swimming: Differences in stroke phases, arm - leg coordination and velocity fluctuation due to event, gender and performance level in breaststroke," Sport. Biomech., vol. 3, no. 1, pp. 15-27, 2004, doi: $10.1080 / 14763140408522827$.

[23] E. Marheni, M. Ridwan, A. S, E. Purnomo, and V. Soniawan, "Meningkatkan Gairah Belajar PJOK Siswa Pasca Pandemi Covid-19," Suluah Bendang J. Ilm. Pengabdi. Kpd. Masy., vol. 20, no. 3, p. 149, 2020, doi: 10.24036/sb.0590. 
[24] G. J. Thomas, "Effective teaching and learning strategies in outdoor education: findings from two residential programmes based in Australia," J. Adventure Educ. Outdoor Learn., vol. 19, no. 3, pp. 242-255, 2019, doi: $10.1080 / 14729679.2018 .1519450$.

[25] R. Trigueros, J. M. Aguilar-Parra, R. López-Liria, and P. Rocamora, "The dark side of the self-determination theory and its influence on the emotional and cognitive processes of students in physical education," Int. J. Environ. Res. Public Health, vol. 16, no. 22, pp. 1-11, 2019, doi: 10.3390/ijerph16224444.

[26] V. Correia, J. Carvalho, D. Araújo, E. Pereira, and K. Davids, "Principles of nonlinear pedagogy in sport practice," Phys. Educ. Sport Pedagog., vol. 24, no. 2, pp. 117-132, 2019, doi: 10.1080/17408989.2018.1552673.

[27] I. Syrmpas and N. Digelidis, "Physical education student teachers' experiences with and perceptions of teaching styles," J. Phys. Educ. Sport, vol. 14, no. 1, pp. 52-59, 2014, doi: 10.7752/jpes.2014.01009.

[28] A. Chatzipanteli, "Inclusion Teaching Style and Metacognition in Physical Education Classes," Educ. J., vol. 1, no. 1, p. 51, 2018, doi: 10.31058/j.edu.2018.11004.

[29] T. A. Farley, R. A. Meriwether, E. T. Baker, J. C. Rice, and L. S. Webber, "Where do the children play? The influence of playground equipment on physical activity of children in free play," J. Phys. Act. Heal., vol. 5, no. 2, pp. 319-331, 2008, doi: 10.1123/jpah.5.2.319.

[30] A. Ellaway, A. Kirk, S. Macintyre, and N. Mutrie, "Nowhere to play? The relationship between the location of outdoor play areas and deprivation in Glasgow," Heal. Place, vol. 13, no. 2, pp. 557-561, 2007, doi: 10.1016/j.healthplace.2006.03.005.

[31] H. L. Burdette and R. C. Whitaker, "Resurrecting Free Play in Young Children," Arch. Pediatr. Adolesc. Med., vol. 159, no. 1 , p. 46, 2005, doi: 10.1001/archpedi.159.1.46.

[32] A. Dizdarevic, A. Mujezinovic, and H. Memisevic, "Comparison of teachers attitudes towards inclusive education in Bosnia and Herzegovina and european union," J. Spec. Educ. Rehabil., vol. 18, no. 1-2, pp. 92-108, 2017, doi: $10.19057 /$ jser.2017.21.
[33] A. M. Correia and V. S. Teixeira, "The will and the way of inclusive education in Macao," Asian Educ. Dev. Stud., vol. 6, no. 4, pp. 401-413, 2017, doi: 10.1108/AEDS-05-2016-0040.

[34] Y. Macejková, D. Masaryková, and J. Labudová, "Proportionality of load during swimming lessons of adults," Fit. Perform. J., vol. 7, no. 3, pp. 180-184, 2008, doi: 10.3900/fpj.7.3.180.e.

[35] B. Ried, G. M. Rodrigues, and C. M. Meira, "Analysis of previous perceptual and motor experience in breaststroke kick learning," Hum. Mov., vol. 16, no. 4, pp. 181-188, 2015, doi: 10.1515/humo-2015-0044.

[36] E. Marheni et al., "Discipline Levels of Junior Students during Physical Education Lessons at Schools," Int. J. Hum. Mov. Sport. Sci., vol. 9, no. 4, pp. 635-641, 2021, doi: 10.13189/saj.2021.090405.

[37] M. Goudas, S. Biddle, K. Fox, and M. Underwood, "It Ain't What You Do, It's the Way that You Do It! Teaching Style Affects Children's Motivation in Track and Field Lessons," Sport Psychol., vol. 9, no. 3, pp. 254-264, 2016, doi: 10.1123/tsp.9.3.254.

[38] M. J. Lee, J. Whitehead, N. Ntoumanis, and A. Hatzigeorgiadis, "Relationships among values, achievement orientations, and attitudes in youth sport," J. Sport Exerc. Psychol., vol. 30, no. 5, pp. 588-610, 2008, doi: 10.1123/jsep.30.5.588.

[39] E. Avramidis and B. Norwich, "Teachers' attitudes towards integration/inclusion: A review of the literature," Eur. J. Spec. Needs Educ., vol. 17, no. 2, pp. 129-147, 2002, doi: $10.1080 / 08856250210129056$

[40] K. Burke and C. Sutherland, "Attitudes Toward Inclusion: Knowledge Vs. Experience,” Education, vol. 125, no. 2, pp. 163-172, 2004, [Online]. Available: http://vnweb.hwwilso nweb.com/hww/jumpstart.jhtml?recid=c84804dfd2d2953e 988f1b4448254167906560440245867c20893151cf666cb2 $\& \mathrm{fmt}=\mathrm{C}$.

[41] L. Florian, "Preparing teachers to work in "schools for all," Teach. Teach. Educ., vol. 25, no. 4, pp. 533-534, 2009, doi: 10.1016/j.tate.2009.02.004 